\title{
Reabilitação de Begonia sylvestris (Begoniaceae)
}

Rehabilitation of Begonia sylvestris (Begoniaceae)

Eliane de Lima Jacques ${ }^{1}$

\begin{abstract}
Resumo
Nesse estudo Begonia sylvestris A.DC. (Begoniaceae) é reabilitada à categoria de espécie. Este táxon assemelha-se a B. arborescens Raddi, B. hookeriana Gardn. e B. lunaris E.L.Jacques, com os quais compartilha a semelhança no porte, na forma da lâmina foliar e na caducidade das estípulas. Uma descrição completa, com ilustração e comentários taxonômicos, é apresentada.
\end{abstract}

Palavras-chave: Floresta Atlântica, nomenclatura, Rio de Janeiro, taxonomia.

\begin{abstract}
In this study Begonia sylvestris A.DC. (Begoniaceae) is re-established to species rank. This species resembles B. arborescens Raddi, B. hookeriana Gardn. and B. lunaris E.L.Jacques which share growth pattern, similar leaf shape and deciduous stipules. A complete description, with illustration and taxonomic comments, is provided.
\end{abstract}

Key words: Atlantic rainforest, nomenclature, Rio de Janeiro, taxonomy.

\section{Introdução}

Durante uma pesquisa de campo, realizada numa área preservada da Floresta Atlântica do Rio de Janeiro, pôde-se observar uma espécie que apresentava afinidades morfológicas com Begonia arborescens Raddi, B. hookeriana Gardn. e B. lunaris E.L.Jacques. Uma vez que recentes estudos taxonômicos em Begonia L. têm revelado novos táxons para a Floresta Atlântica (Gomes da Silva \& Mamede 2000; Jacques 2008; Kollmann 2008; Jacques \& Kollmann 2009), acreditava-se que essa espécie era mais uma novidade para a Ciência. Entretanto, a análise de exemplares de todos os binômios associados às espécies supracitadas, assim como do tipo nomenclatural de $B$. sylvestris A.DC., permitiu que se elucidasse a questão.

Begonia arborescens foi descrita por Raddi (1820). Posteriormente, Candolle (1859) descreveu B. sylvestris, com base em material coletado por Riedel em Macaé, Rio de Janeiro. No tratamento taxonômico da família Begoniaceae para o Prodromus, Candolle (1864) considerou $B$. arborescens e $B$. sylvestris como espécies distintas. Nas diagnoses apresentadas nessa obra (pp. 376 e 378), B. arborescens e B. sylvestris possuem diferenças na forma e no tamanho das folhas (obovadas, com 12,7-20,3 $\times 5-12,7 \mathrm{~cm}$, e ovadas, com 15,2-20,3 × 7,6-12,7 cm, respectivamente) e no tamanho da cápsula (ca. 6,7×5,6-6,7 mm e ca. 11,2× $13,5 \mathrm{~mm}$, respectivamente).

Smith \& Wasshausen (1984) apresentaram a sinonimização de algumas espécies de Begonia, porém subordinaram $B$. sylvestris à sinonímia de $B$. arborescens sem justificativa para essa decisão taxonômica, contrariando ao que adotaram para a sinonimização de outros táxons.

$\mathrm{Na}$ análise de uma exsicata depositada no herbário K, identificada como B. sylvestris, evidenciase a presença de duas espécies distintas, coletadas por Riedel e procedentes de localidades diferentes. Um dos ramos da exsicata, o que apresenta frutos e várias folhas soltas, pertence a $B$. arborescens, coletado em Vila Rica, Minas Gerais (Riedel 1456), e o outro ramo, o que possui uma inflorescência, é o isótipo de B. sylvestris (Riedel 863).

A maior precisão na circunscrição de $B$. sylvestris é justificada pelo exame do material-tipo depositado em G-DC, pela análise de outras coleções com frutos, localizadas nos herbários RB e RBR, e pela pesquisa de campo.

Este trabalho tem como objetivo contribuir para a taxonomia da família Begoniaceae, uma vez que reabilita Begonia sylvestris à categoria de espécie, fornecendo uma descrição mais detalhada e ilustrando o táxon. 


\section{Material e Métodos}

O presente trabalho foi baseado na análise de materiais de Begonia arborescens, B. hookeriana, $B$. lunaris e $B$. sylvestris depositados nos herbários B, G-DC, GUA, HB, K, R, RB, RBR, SP, SPF e UEC, perfazendo um total de 143 exsicatas, além do estudo de populações dessas espécies no campo. As siglas dos herbários estão de acordo com Thiers (2010). A descrição dos caracteres qualitativos e quantitativos foi baseada exclusivamente no material examinado.

\section{Resultados e Discussão}

Begonia sylvestris A.DC., Ann. Sci. Nat., Sér. 4, Bot. 11: 140. 1859. Tipo: BRASIL. RIODEJANEIRO: “in sylvis humidis Macahé”, Riedel 863 (holótipo $\mathrm{LE}$; isótipos G-DC!, $\mathrm{K}$ ! p.p.).

Fig. 1

Ervas a subarbustos eretos, terrestres, umbrófilos, ca. 1,5 m alt.; cistólitos presentes, melhor visualizados nas estruturas hialinas, como as bractéolas e tépalas; caule, na região distal, estípulas e pecíolos com esparsos tricomas simples e glandulares. Caule ereto, entrenós 5,3-10 cm compr. na porção distal, verdes, pubérulos a glabrescentes na porção distal, tricomas simples, adpressos e glandulares. Pecíolos 1,7-3,5 cm compr., cilíndricos, verdes a avermelhados, pubérulos ao longo de toda a extensão, tricomas simples adpressos e tricomas glandulares esparsos. Estípulas 1,3-2,5(3-4) × 0,7-0,8(-1,4) $\mathrm{cm}$, cedo-caducas, naviculares, ápice apiculado, carnosas, esverdeadas, face abaxial pubérula, tricomas simples, adpressos, mais densamente distribuídos na base. Folhas 16-27(-30-35) x (6-8-)10-15 cm, assimétricas, transversalmente elípticas, lobo basal presente, basifixas, papiráceas, discolores, face adaxial verde-escura, lustrosa, com tricomas glandulares laxamente distribuídos, face abaxial sanguínea, com tricomas glandulares densamente dispostos, próximos às nervuras principais, base cordada, ápice acuminado, margem serrulada; nervuras principais 1(-4), nervação craspedódroma, ocasionalmente actinódroma. Cimeiras ca. $15 \mathrm{~cm}$ compr. (incluindo o pedúnculo), eretas, 8-ramificadas, ca. 560 flores; pedúnculo ca. $8 \mathrm{~cm}$ compr., cilíndrico, vináceo, região do nó verde, pubérulo. Brácteas caducas, não vistas. Flores estaminadas ca. $5 \mathrm{~mm}$ compr. (incluindo o pedicelo), pouco vistosas, levemente aromáticas, alvas, pedicelo $2-3 \mathrm{~mm}$ compr., tépalas 4 , reflexas na antese, externas ca. $4 \times 2-3 \mathrm{~mm}$, ovadas, região central da face abaxial com emergências mameliformes, internas 2,5-3×
0,8-1 mm, espatuladas, glabras, estames 15-20, ca. $2 \mathrm{~mm}$ compr., amarelos, filetes ca. $1 \mathrm{~mm}$ compr., livres, anteras ca. $1 \mathrm{~mm}$ compr., espatuladas, conectivo obtuso. Flores pistiladas ca. $15 \mathrm{~mm}$ compr. (incluindo o pedicelo), pouco vistosas, levemente aromáticas, alvas, pedicelo ca. $8 \mathrm{~mm}$ compr., pubérulo; profilos 2, ovados, diminutos, 0,3-1 mm compr., localizados ca. $1 \mathrm{~mm}$ abaixo do hipanto, margem inteira, persistentes; tépalas 5 , eretas na antese, levemente desiguais, 3 maiores e 2 menores, 3-5 ×0,8-2 mm, elípticas, margem inteira, glabras; ovário trilocular, $4-5 \times$ ca. $6 \mathrm{~mm}$, elíptico, alvo, com tricomas glandulares diminutos, alas planas, placenta inteira; estiletes bifurcados, ca. $3 \mathrm{~mm}$ compr., espiralados, cilíndricos, amarelos, estigmas 3, papilas estigmáticas recobrindo toda a extensão do estilete. Cápsulas trialadas, 9-15 × 9-17 mm, transversalmente elípticas, pêndulas na infrutescência, região locular elíptica, 3-4 mm larg., pedicelo 1,4-2,4 cm compr., com tricomas glandulares e simples, pubérulo, alas 5-7 mm larg., semelhantes entre si. Sementes oblongas.

Material examinado: BRASIL. RIO DE JANEIRO: Silva Jardim, Reserva Biológica de Poço das Antas, 17.VII.1997, fr., L. Sylvestre et al. 1319 (RB); margens do Rio São João, 30.V.1982, fr., G. Martinelli \& H.C.Lima 8502 (RB). Cachoeiras de Macacu, Reserva Ecológica de Guapiaçu, 23.II.2009, fl. e fr., E.L.Jacques et al. 1740 (RB, RBR).

Material adicional selecionado: Begonia arborescens Raddi: BRASIL. RIO DE JANEIRO: 1835, C. Gaudichaud 1065 (B). Paineiras, 11.X.1979, CM.S. Lira 99 (GUA). Nova Friburgo, Teodoro de Oliveira, 26.XI.1990, E.L. Jacques et al. 193 (RB). Nova Iguaçu, Reserva Biológica do Tinguá, 18.IV.2007, A.V.S. Couto et al. 16 (RBR). Petrópolis, Rocio, 27.I.1968, D. Sucre 2233 (HB). Teresópolis, Serra dos Órgãos, XII.1896. E. Ule s.n. (R 37058). Begonia hookeriana Gardn.: BRASIL. RIO DE JANEIRO: Angra dos Reis, Fazenda Japuhyba, 19.III.1951, M. Kuhlmann 2614 (SP). Parati, Morro do Corisco, 27.VI.1995, M.D.Campos 35 (RB); praia das Laranjeiras, 15.XI.1993, M.R. Barbosa 29152 (UEC). Teresópolis, Represa dos Guinle, 31.I.1978, A.H. Gentry 916 (RB). SÃO PAULO: Ubatuba, estrada TaubatéUbatuba, 3.II.1996, H.F.Leitão Filho et al. 34631 (SPF). Begonia lunaris E.L.Jacques: BRASIL. RIO DE JANEIRO: Cachoeiras de Macacu, Estação Ecológica Estadual do Paraíso, D. Araújo et al. 1068 (GUA); Rio Paraíso, vale do rio Falcão, 22.XI.1991, L. Sylvestre et al. 689 (RB); Rio Paraíso, próximo à represa da CEDAE, 3.IX.2007, E.L.Jacques et al. 1671 (RBR).

Begonia sylvestris caracteriza-se por ser uma erva ou um subarbusto ereto, com cerca de 1,5 m de altura, porção distal do caule, estípulas e pecíolos pubérulos, indumento constituído de tricomas 


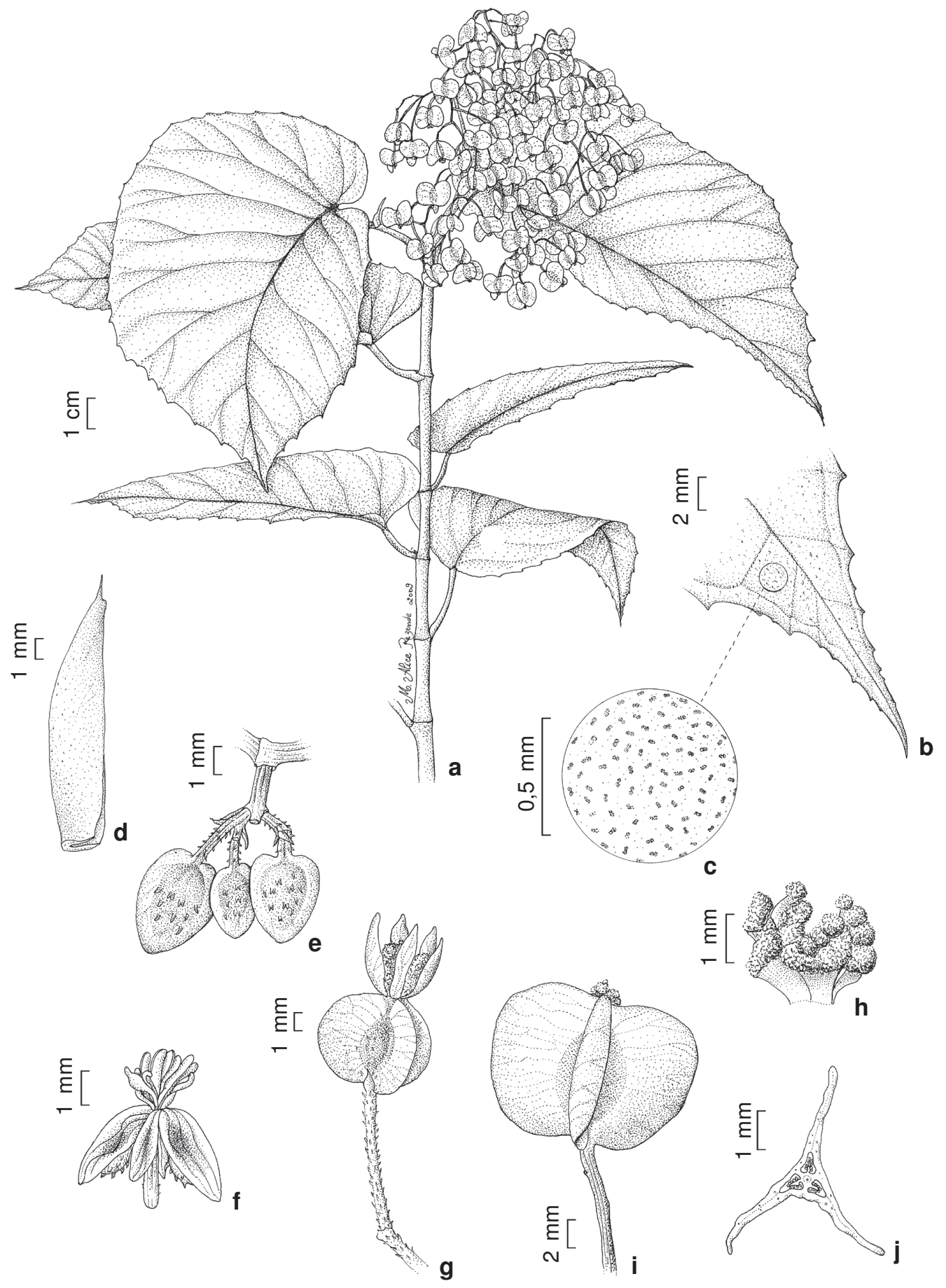

Figura 1 - Begonia sylvestris A.DC. - a. ramo fértil; b. ápice foliar; c. detalhe da lâmina foliar, evidenciando os cistólitos; d. estípula, vista lateral; e. inflorecência parcial com botões florais estaminados, evidenciando as emergências mameliformes; f. flor estaminada, evidenciando as tépalas reflexas; g. flor pistilada aberta, evidenciando as tépalas eretas; h. ápice do ramo do estilete; i. cápsula com estiletes persistentes; j. secção transversal do ovário (Jacques et al. 1740).

Figure 1 - Begonia sylvestris A.DC. - a. flowering branch; b. leaf apex; c; leaf detail showing cystoliths; d. stipule, side view; e. parcial inflorescence with buds of staminate flowers, showing mammeliform emergencies; f. staminate flower, showing reflexed tepals; g. pistillate flowers in anthesis, showing erects tepals; h. style branch apex; i. capsule with persistent styles; j. cross section of ovary (Jacques et al. 1740). 
simples e glandulares esparsamente distribuídos, folhas transversalmente elípticas, com lobo basal, face abaxial sanguínea, e cápsulas 9-15×9-17 mm, transversalmente elípticas.

Begonia sylvestris assemelha-se a $B$. arborescens, $B$. hookeriana e $B$. lunaris, com as quais compartilha a semelhança no porte da planta, na forma da lâmina foliar e na caducidade das estípulas.

Em material herborizado, se este não apresentar frutos, Begonia sylvestris pode ser confundida com $B$. arborescens. Entretanto, $B$. sylvestris possui folhas transversalmente elípticas, assimétricas, com o grau de assimetria variando de acordo com o tamanho do lobo basal, face abaxial com tricomas glandulares microscópicos, nós distais sem anel de tricomas e estípulas e pecíolos pubérulos ao longo de toda a extensão; B. arborescens apresenta folhas obovadas, simétricas, nervura principal da face abaxial com tricomas simples, nós distais com um anel de tricomas simples, estípulas pilosas nas nervuras principais, pecíolos pubérulos na porção distal e glabros na proximal. No entanto, quando observada no seu habitat natural, B. sylvestris pode ser prontamente diferenciada de $B$. arborescens devido ao porte mais delicado, a coloração sanguínea na face abaxial das folhas e frutos maiores $(9-15 \times 9-17$ vs. 4-6 × 6-9 mm) (Tab. 1).

Begonia sylvestris compartilha com $B$. lunaris a forma transversalmente elíptica das folhas. Entretanto, distingue-se prontamente de $B$. lunaris pela forma e comprimento das estípulas (navicular, 1,3-2,5(3-4) cm compr. vs. oblonga a triangular, 2,5-6,1 cm compr.), pelas cápsulas transversalmente elípticas ( $v s$. elípticas) e pelas alas planas ( $v s$. inflexas) (Tab. 1).

Begonia sylvestris compartilha com $B$. hookeriana a forma transversalmente elíptica dos frutos, porém $B$. hookeriana apresenta o indumento constituído de tricomas estrelados (vs. tricomas simples e glandulares) (Tab. 1).

Tabela 1 - Comparação de Begonia sylvestris com espécies relacionadas.

Table 1 - Comparision of Begonia sylvestris with related species.

\begin{tabular}{|c|c|c|c|c|}
\hline Características & Begonia arborescens & Begonia hookeriana & Begonia lunaris & Begonia sylvestris \\
\hline Tipo de tricomas & simples e glandulares & estrelados & glandulares & simples e glandulares \\
\hline $\begin{array}{l}\text { Nó distal (anel } \\
\text { de tricomas) }\end{array}$ & presente & ausente & ausente & ausente \\
\hline \multicolumn{5}{|l|}{ Estípula } \\
\hline forma & elíptica & oblonga & oblonga a triangular & navicular \\
\hline comprimento $(\mathrm{cm})$ & $1,3-3,3(-4,9)$ & $0,8-1,5(-1,7)$ & $2,5-6,1$ & $1,3-2,5(3-4)$ \\
\hline indumento & $\begin{array}{l}\text { tricomas simples } \\
\text { somente próximo } \\
\text { à nervura }\end{array}$ & $\begin{array}{l}\text { tomentoso-ferrugínea } \\
\text { ao longo de toda a } \\
\text { extensão }\end{array}$ & $\begin{array}{l}\text { tricomas glandulares ao } \\
\text { longo de toda a extensão, } \\
\text { esparsos na face dorsal a } \\
\text { glabrescentes na ventral }\end{array}$ & $\begin{array}{l}\text { tricomas simples ao } \\
\text { longo de toda a } \\
\text { extensão, mais } \\
\text { densamente na base }\end{array}$ \\
\hline Pecíolo (indumento) & $\begin{array}{l}\text { tricomas simples } \\
\text { na porção distal e } \\
\text { glabro na proximal }\end{array}$ & $\begin{array}{l}\text { tricomas estrelados } \\
\text { em toda a extensão }\end{array}$ & $\begin{array}{l}\text { tricomas glandulares } \\
\text { esparsos em toda } \\
\text { a extensão }\end{array}$ & $\begin{array}{l}\text { pubérulo, tricomas } \\
\text { simples adpressos e } \\
\text { glandurares esparso } \\
\text { em toda a extensão }\end{array}$ \\
\hline \multicolumn{5}{|l|}{ Folha } \\
\hline tamanho $(\mathrm{cm})$ & $12-20,5 \times 5-9,3$ & $\begin{array}{l}(16-) 22-45 \times \\
(6,5-) 9-21\end{array}$ & $\begin{array}{l}(15-) 22-34 \times \\
(6,7-) 10-15\end{array}$ & $\begin{array}{l}16-27(-30-35) \times \\
(6-8-) 10-15\end{array}$ \\
\hline $\begin{array}{l}\text { indumento (face } \\
\text { abaxial) }\end{array}$ & $\begin{array}{l}\text { tricomas simples } \\
\text { na nervura mediana }\end{array}$ & $\begin{array}{l}\text { tormentosa por } \\
\text { toda a face }\end{array}$ & $\begin{array}{l}\text { tricomas glandulares } \\
\text { esparsos }\end{array}$ & $\begin{array}{l}\text { tricomas glandulares } \\
\text { esparsos }\end{array}$ \\
\hline Estames (número) & $27-32$ & $47-60$ & $55-65(-80)$ & $15-20$ \\
\hline $\begin{array}{l}\text { Cápsula } \\
\text { forma }\end{array}$ & $\begin{array}{l}\text { transversalmente } \\
\text { elíptica }\end{array}$ & $\begin{array}{l}\text { transversalmente } \\
\text { elíptica }\end{array}$ & elíptica & $\begin{array}{l}\text { transversalmente } \\
\text { elíptica }\end{array}$ \\
\hline tamanho $(\mathrm{mm})$ & $4-6 \times 6-9$ & $6-10 \times 10-14$ & $20-27 \times 15-18$ & $9-15 \times 9-17$ \\
\hline alas (posição) & planas & planas & inflexas & planas \\
\hline
\end{tabular}




\section{Agradecimentos}

Aos curadores e funcionários dos herbários, que permitiram o estudo de suas coleções. Ao Arthur Vinícius dos Santos Couto, Jens Wesenberg e Rolf Engelmann, que gentilmente me acompanharam na pesquisa de campo. A Sra. Raquel e ao Sr. Nicholas Locke, pela autorização de coleta na Reserva Ecológica de Guapiaçu. A Maria Alice Rezende, pelo preparo das ilustrações.

\section{Referências}

Candolle, A. 1859. Mémoire sur la famille du Begoniacées. Annales des Sciences Naturelles Botanique, Sér. 4, 11: 93-149.

Candolle, A. 1864. Begoniaceae. In: Candolle, A. de (ed.). Prodromus Systematis Naturalis Regni Vegetabilis. Victoris Masson ET Fils, Paris. Vol.15, pars. 1. Pp. 266-408.

Gomes da Silva, S.J. \& Mamede, M.C.H. 2000. A new species of Begonia (Begoniaceae) from the Atlantic
Coastal Forest in the State of São Paulo, Brazil. Novon 10: 22-25.

Jacques, E.L. 2008. Begonia lunaris E. L. Jacques (Begoniaceae), uma nova espécie para o estado do Rio de Janeiro, Brasil. Rodriguésia 59: 259-263.

Jacques, E.L. \& Kollmann, L.J.C. 2009. Begonia caparaoensis (Begoniaceae), a new endemic species from the Atlantic Forest in the State of Minas Gerais, Brazil. Novon 19: 172-174.

Kollmann, L.J.C. 2008. Duas novas espécies de Begonia (Begoniaceae) do Espírito Santo, Brasil. Rodriguésia 59: $155-160$.

Raddi, G. 1820. Quaranta piante nuove del Brasile. Mem. Mat. Fis. Soc. Ital. Sci. Modena 18: 27-31.

Smith, L.B. \& Wasshausen, D.C. 1984. Notes on Begoniaceae - III. Phytologia 52: 465-473.

Thiers, B. 2010. Index Herbariorum: A global directory of public herbaria and associated staff. New York Botanical Garden's Virtual Herbarium. Disponível em <http://sweetgum.nybg.org/ih>. Acesso em 12 maio 2010. 